\title{
JACQUES DERRIDA: EXPERIENCIA DE LA ALTERIDAD
}

\author{
Esther ZARZo \\ Universidad de Alicante
}

\begin{abstract}
Resumen
El presente trabajo ofrece una introducción al pensamiento derridiano desde la experiencia de la lengua, hasta el por-venir de la deconstrucción, pasando por la crítica a la Metafísica de la presencia y su Mitología blanca. La primera parte expone la experiencia de la lengua vivida por Jacques Derrida a fin de utilizarla como esquema para explicar las críticas fundamentales al fonocentrismo y la estrategia de lectura-escritura deconstructiva. Se ponen en relación, por tanto, los conceptos de phoné, grammé, différance, doble gesto y testimonio. La segunda profundiza en la crítica a la ontología de la presencia articulando los conceptos de presencia-ausencia y alteridad. La tercera explicita la dimensión ética de la deconstrucción y aborda la hospitalidad y la necesidad de cuestionamiento constante de los efectos de sentido vigentes que justifican y perpetúan el estado de cosas en los ámbitos metafísico, epistemológico y antropológico.
\end{abstract}

Palabras clave: Logocentrismo, fonocentrismo, Metafísica de la presencia, alteridad, deconstrucción, ética.

\begin{abstract}
The present paper offers an introduction to Derridian thought from language experience to deconstruction, going through the review of Metaphysics of presence and White mythology. The first part explains language experience undertook by Jacques Derrida in order to use it as an outline to offer an explanation to the fundamental review of phonocentrism and the strategy of deconstructive reading-writing. Therefore, the concepts of phoné, grammé, différance, double_blind and testimony are explained. The second part deals with ontology articulating the concepts of presence-absence and alterity. The third part explicitly states Ethic dimension of deconstruction and addresses hospitality and the need of constant questioning of the current sense effects that justify and perpetuate the state of things in metaphysical, epistemological and anthropological levels.
\end{abstract}

Keywords: Logocentrism, phonocentrism, Metaphysics of presence, Alterity, Deconstruction, Ethics. 


\section{CRÍticA AL LOGO-FONOCENTRISMO}

No tengo más que una lengua y no es la mía ${ }^{1}$.

Con esta fórmula inicia Jacques Derrida El Monolingüismo del otro para dar testimonio de su experiencia del límite de la lengua a través de la escritura. Nacido en I930 en la colonia francesa de El-Biar, cerca de Argel, y bautizado por el rito judío como Jackie Élie, Derrida aprende como lengua materna el francés, pero un francés impuro de colono, impuesto o arrebatado según el poder hegemónico, tan intermitente como su ciudadanía, que le define como extranjero en su hogar y le imposibilita expresar su diferencia propia arraigada en una tradición familiar judío-sefardí, de origen español y exiliada después de la reconquista; unas raíces veladas pero latentes en ese primer nombre hebreo, Jacki; y en el segundo, profético, Élie.

Desde el inicio Derrida se encuentra frente a la dicotomía de aceptar la limitación al concepto impuesto y vivir protegido gregariamente con los demás excluidos o bien socializarse para sufrir la falta de reconocimiento por ambas partes. Pero en 1952 comienza sus estudios de Filosofía en París y descubre que tal aporía solo es un falso dilema, pues en la metrópoli colonizadora que domina Argelia a distancia no existe la pureza identitaria que justifica la superioridad natural y la relación de poder vivida por el colono, sino más bien identidades plurales no homogeneizables. Donde se supone que debería estar la tesis resulta que solo hay una prótesis: la identidad dominante es un efecto de sentido que se impone ocultando su impureza. De aquí el subtítulo de la obra El Monolingüismo del otro o la prótesis de origen, donde el testimonio derridiano despliega las dos caras del efecto de sentido: la vivencia del límite a través de la lengua como franco-magrebí, como judío-argelino, le lleva a comprender que su monolingüismo le viene de otro, pero también que tal monolingüismo, tal unicidad, pura e incontaminada, no se da, antes bien es un mero efecto erigido sobre la exclusión injustificada de un "otro" al que se define arbitraria e interesadamente como impuro.

1 J. Derrida, El Monolingüismo del otro o la prótesis de origen, trad. de H. Pons, Buenos Aires, Manantial, 1997, p. 13. Disponible edición digital en el sitio web Derrida en castellano, <https:// redaprenderycambiar.com.ar/derrida/textos/monolinguismo.htm>, [consulta 30/04/2020]. 
Nunca se habla más que una sola lengua. Nunca se habla una sola lengua ${ }^{2}$. Nunca se habla solo una lengua, o más bien, no hay idioma puro ${ }^{3}$.

Sobre esta experiencia, Derrida diseña una estrategia de lectura-escritura particular, ya que, si por una definición impuesta se es el excluido, hasta el punto de no tener una lengua en la cual pronunciarse a uno mismo de forma diferencial, habrá que aprender a usar esa lengua dominante de un modo indirecto, con un doble gesto que fuerce al francés a decir y desdecirse en el mismo acto, que permita al colono hablar y no identificarse con lo marginal; y así, dar voz al silenciado en cuya negación se funda el estatus del dominante.

Si se quiere afectar a la lengua de algún modo es necesario hacerlo de manera refinada, respetando en la irrespetuosidad su ley secreta. Es eso, la fidelidad infiel: cuando violento la lengua francesa, lo hago en el refinado respeto de lo que considero un requerimiento (injonction) de esa lengua, en su vida, en su evolución ${ }^{4}$.

Dicha estrategia de lectura-escritura vino a denominarse deconstrucción, término conflictivo por sus connotaciones destructivas, y por el que Derrida muestra su disconformidad en numerosas ocasiones ${ }^{5}$, haciendo hincapié en que su propuesta plantea desnaturalizar las bases de los efectos de sentido que fundamentan la cosmovisión vigente, unos sentidos que se han "sedimentado", imponiendo un logos concreto a todo lo demás de forma excluyente. La estrategia derridiana procura la "des-sedimentación” de sentidos que perpetúan el estado de cosas, y con ello una "diseminación" o liberación de los sentidos silenciados por esa jerarquía arbitraria que se autoproclama como natural ${ }^{6}$.

2 J. Derrida, ob. cit., 1997, p. 19.

3 Ibid., p. 21.

4 J. Derrida, Estoy en guerra contra mí mismo, entrevista a J. Derrida realizada por J. Birnbaum, publicada en Le Monde, 19/08/04; en A parte rei. Revista de Filosofía, trad. de S. Royo, p. 5. Disponible en línea <http://serbal.pntic.mec.es/ cmunoz11/entrevista37.pdf>, [consulta: 18/04/2020].

5 J. Derrida, “Carta a un amigo japonés”, en El tiempo de una tesis. Deconstrucción e implicaciones conceptuales, trad. de. C. de Peretti, Barcelona, Proyecto A Ediciones, 1997. En Derrida en castellano, <https://redaprenderycambiar.com.ar/derrida/textos/carta_japones.htm>, [consulta 30/04/2020].

6 C. de Peretti, “Deconstrucción”, entrada del Diccionario de Hermenéutica, dir. A. Ortiz-Osés y P. Lanceros, Bilbao, Universidad de Deusto, 1998. En Derrida en castellano, <https://redaprenderycambiar.com.ar/derrida/comentarios/peretti_2.htm>, [consulta 30/04/2020]. 
Diseminación no quiere decir nada en última instancia [...] marca una multiplicidad irreductible y generativa. El suplemento y la turbulencia de una cierta ausencia fracturan el limite del texto, probiben su formalización exhaustiva $y$ clausurante ${ }^{7}$.

Queda patente que la intención derridiana no es intrínsecamente destructiva. Por principio, la diseminación asume que la lengua materna, identitaria y origen del sentido no existe de forma pura; por tanto, la estrategia de lectura-escritura deconstructiva lejos de querer destruir o eliminar la lengua dominante, acepta que siempre se está hablando una lengua dada por otro y que no hay un lugar desde el cual pronunciarse a uno mismo. De hecho, tampoco se propone pronunciar lo excluido, ya que, si lo hiciera habría conseguido asimilar a ese otro radicalmente distinto: si el francés lo puede pronunciar es que sólo es un colono asimilado. Entre estas dos posturas incide el movimiento de resistencia derridiano para señalar la asimilación y silenciamiento del otro por parte del dominante, y abrir un espacio de reconocimiento a ese otro justo en la asimetría entre lo dicho y lo indecible. Desde la perspectiva derridiana, no se puede salir de la dialéctica a un espacio prístino de reconocimiento, pero en esa jerarquía entre sentido dominante / silenciado dominado siempre resta un irreductible que clama desde el silencio su reconocimiento; y la deconstrucción asume la tarea de desnaturalizar las pretensiones purificadoras, desvelar la contaminación originaria del que se pretende puro, dar espacio a que lo otro se dé en su forma propia, y con ello brindarle reconocimiento.

Dicho lo anterior, es fácil explicitar la tesis de El Monolingüismo del otro. No sólo Derrida cuestiona la autoproclamada pureza del colonizador cultural y la política lingüística que uniformiza e impone un concepto identitario de colonizado; sino que descubre el mecanismo de dicha exclusión. El poder colonial se erige lingüísticamente por oposición sobre el par conceptual compuesto por "colono" frente a "colonizador", pero tales conceptos no describen una realidad, el "colono" no lo es por una naturaleza intrínseca, es "colono" por su relación con el colonizador, quien

7 J. Derrida, Posiciones, entrevista con J. L. Houdebine y G. Scarpetta, trad. de M. Arranz, Valencia, Pre-textos, 1977, p. 53. En Derrida en castellano: <https://redaprenderycambiar.com.ar/ derrida/textos/posiciones.htm>, [consulta 30/04/2020]. 
le define por negación, ya que "ser colono" consiste en "no ser colonizador", en "ser lo dominado", "lo silenciado", "lo otro", es decir, "lo excluido" por el dominante que impone su sentido, y con ello, su logocentrismo. No obstante, al problematizar los sentidos dominantes, se percibe la falta de reconocimiento interesada de una realidad distinta, momento en que la supuesta naturalidad y neutralidad descriptiva del sistema de la mismidad queda injustificada, abriéndose un espacio para que lo otro se dé, para la in-venida de lo otro. Y dice conscientemente in-venida, termino forzado por el doble gesto derridiano, a fin de decir y dejar espacio a lo no dicho simultáneamente, y resaltar la imposibilidad de provocar a lo que es radicalmente distinto, debido a que no se puede prever "lo otro" desde el sistema "del mismo".

En este último punto radica el riesgo, pero también la apertura ética de la "des-sedimentación", pues si se desnaturalizan los conceptos excluyentes, el resultado sólo puede ser una reformulación del par de opuestos y por tanto de la jerarquía que funda el sistema. No se trata de abrir un espacio para que "un otro", perfectamente asimilable, se dé; se trata de abrir espacio al acontecimiento singular e irrepetible de ser con lo otro que in-venga. Se revela ahora el sentido profundo el término de testimonio, porque si asumimos que el otro sólo se da en su forma propia, irreductible a las categorías identitarias, significa que solo se manifiesta como una alteración en las categorías de la mismidad, un acontecimiento del cual solo bay testimonio.

$\mathrm{El}$ acontecimiento no se reduce al hecho de que algo acontezca. Es una singularidad absolutamente otra [...] para el que se carece de horizonte de espera. [...] Y siempre cabe la posibilidad de que el arribante no llegue9 .

$Y$ este es el razonamiento que está en la base del término derridiano por excelencia, différance ${ }^{10}$, síntesis conceptual y puesta en práctica de su

8 J. Derrida, Psyqué: invenciones del otro, en AA. VV., Diseminario: La deconstrucción, otro descubrimiento de América, Montevideo, XYZ Ediciones, 1987. En Derrida en castellano <http://www. jacquesderrida.com.ar/textos/psyche.htm>, [consulta: 30/04/2020].

9 J. Derrida, La deconstrucción de la Actualidad, entrevista con J. Derrida, Passages, núm. 57, septiembre 1993, pp. 60-75. Palabras recogidas por S. Douailler, É. Malet, C. de Peretti, B. Sohm y P. Vermerem, trad. de C. de Peretti, El Ojo Mocho. Revista de Crítica Cultural, Buenos Aires, núm. 5, Primavera, 1994. En Derrida en castellano: <https://redaprenderycambiar.com.ar/derrida/textos/ artefactualidades.htm>, [consulta 30/04/2020].

10 J. Derrida, “La Différance”, en Márgenes de la filosofía, trad. de C. González Marín, Cátedra, 
metodología. Efectivamente, en la palabra différance se da una diferencia respecto del término correcto en francés, différence, pero es una diferencia que solo se da en la escritura debido a la homofonía de ambos vocablos. Una variación en la escritura inaudible, de hecho, impronunciable, clama por ser reconocida en su diferencia ${ }^{11}$. En este término se ejemplifica la crítica al fonocentrismo ${ }^{12}$ sostenido por la tradición y desnaturalizado por Derrida en Gramatología ${ }^{13}$.

Brevemente, en esta obra Derrida plantea que, por tradición, los efectos de sentido se han jerarquizado a través de una estructura lingüística que ubica el sentido verdadero y originario sobre la phoné, es decir, sobre la voz, lo pronunciado o pronunciable, y que este sistema obvia realidades que sí se dan con otro modo de ser, concretamente, en forma de escritura silenciosa. Derrida, en cambio, presta atención a la escritura en la cual se da lo otro a la voz, lo impronunciable. La deconstrucción sería la estrategia de lectura escritura que analiza genealógicamente los conceptos y desnaturaliza la jerarquía establecida entre ellos, problematizando o diseminando los sentidos que la sostienen, poniendo en marcha la différance.

Se reconoce claramente la raíz religiosa derridiana, quien entiende el término "religión"14 al estilo ciceroniano como derivado de "relegere": leer atentamente, repasar escrupulosamente. Si en la escritura se da la alteridad en su forma propia, en la lectura silenciosa se revela el secreto impronunciable. Así como la experiencia hebrea se articula a partir del Libro $^{15}$, no como código moral de justicia, sino como ontología; Derrida aborda a través de la lectura-escritura la experiencia de lo dicho y de lo silenciado. Todo ello enmarcado por la experiencia esencial de saberse desde el inicio impuro, exiliado por naturaleza de una tierra prometida

Madrid, 1998, pp. 37-63. En Derrida en castellano: <https://redaprenderycambiar.com.ar/derrida/ textos/la_differance.htm>, [consulta 30/04/2020].

11 J. Derrida, La escritura y la diferencia, trad. de P. Peñalver, Barcelona, Anthropos, 2012.

$12 \mathrm{~J}$. Derrida, La voz y el fenómeno. Introducción al problema del signo en la fenomenología de Husserl, trad. de F. Peñalver, Valencia, Pretextos, 1985.

13 J. Derrida, De la gramatología, trad. de O. del Barco y C. Ceretti, Buenos Aires, S. XXI, 1971.

14 J. Derrida, Fe y Saber/ El siglo y el Perdón, trad. de C. de Peretti y P. Vidarte, Buenos Aires, La Flor, 2003, p. 83. En Derrida en castellano: <https://redaprenderycambiar.com.ar/derrida/textos/ fe_y_saber.htm>, [consulta 30/04/2020].

15 J. Derrida, El libro por venir, Encuentro en Biblioteca Nacional de Francia R. Chartier, B. Stiegler, 20 de marzo de 1997, trad. de C. de Peretti y P. Vidarte. En Derrida en castellano: <https:// redaprenderycambiar.com.ar/derrida/textos/libro_por_venir.htm>, [consulta: 30/04/2020]. 
que siempre estará por-venir, con una la lengua materna de otro que nos funda; que conlleva también el conocimiento de que el sujeto autoproclamado puro y universal sólo es una Mitología blanca ${ }^{16}$ que domina si se desconocen sus inconsistencias, y que el análisis minucioso del vínculo es el punto de intervención para revelar sus intereses.

Por eso Derrida recupera la grammé, la apertura a la escritura: el fin del origen del sentido y el comienzo de la escritura como una ontología donde ocurre algo irreductible a la voz y lo que justifica la vuelta constante al archivo en su búsqueda.

Precisamente para reconocer dicho excedente de sentido, Derrida de nuevo fuerza el lenguaje para articular el término archi-escritura, archi-archivo ${ }^{17}$ a fin de resaltar que en la escritura se archiva lo dicho, pero también el silencio de lo otro. Justo donde se opera el silenciamiento de lo que no puede asumir las categorías de la mismidad dominante, habitan los silenciados de la historia clamando el reconocimiento de su diferencia, y cuyo testimonio jamás será reconocido. Por este motivo, Derrida califica la deconstrucción como tarea inagotable, pues siempre habrá que desnaturalizar lo dicho para abrir espacio a lo por-venir que por definición siempre estará por-venir.

Así pues, y a modo de conclusión de este primer apartado, desde una experiencia de la lengua marcada por la colonización, Derrida elabora una reflexión lingüística en la que aplica la teoría del significado por oposición al problema de la definición, construyendo una crítica al sentido impuesto, logocentrismo, y a la voz privilegiada, fonocentrismo, en la que concluye que los sentidos fundadores de la cosmovisión hegemónica se erigen sobre un mecanismo de definición basado en la identidad excluyente, por el cual un efecto de sentido se impone sobre los demás ocultando su impureza e invisibilizando a los definidos como impuros. Consecuentemente, Derrida diseña un modo de lectura-escritura que opera un doble gesto sobre la grammé, y desnaturaliza dicha jerarquía para atender a lo silenciado en tales efectos de sentido. El desarrollo de este razonamiento lingüístico

16 J. Derrida, "Mitología blanca. La metáfora en el texto filosófico", en Márgenes de la filosofía, ob. cit., pp. 247 y ss.

17 J. Derrida, Mal de archivo. Una impresión freudiana, trad. de P. Vidarte, Madrid, Trotta, 1996. En Derrida en castellano: <https://redaprenderycambiar.com.ar/derrida/textos/mal+de+archivo.htm>, [consulta 30/04/2020]. 
conduce directamente a la reflexión ontológica sobre el ser relacional y la alteridad como crítica a la Metafísica de la presencia.

\section{Crítica a la Metafísica de la Presencia}

Efectivamente, y pese a la dificultad de clasificación de la propuesta derridiana, la postura adoptada en el debate epistemológico de la modernidad sobre la posibilidad o no de atender a la alteridad, o lo otro al sistema tradicional, es clara ${ }^{18}$ : a juicio de Derrida, manteniendo la consistencia con su crítica al logocentrismo, no hay, epistemológicamente, un "afuera" del sistema de dominio, como podía plantear el Pensamiento del afuera de Foucault ${ }^{19}$; y tampoco hay una "heterología pura" como defendería Lévinas ${ }^{20}$, donde la alteridad radical termina siendo dios y nos funda como sus respondedores únicos. Para Derrida hay "heterología contaminada", lo que denominamos el afuera y el adentro, como si fueran entidades contrapuestas, son solo efectos de sentido polarizados y jerarquizados de una misma realidad en su devenir indecidible. La escisión conceptual entre el "afuera” y el "adentro" que da cobertura a otras contraposiciones como la de "ellos" frente a "nosotros" presentan fronteras totalmente artificiales, pues en realidad se habitan, se asedian, por mucho que el efecto de sentido vigente intente mantener su pureza sobre la exclusión permanente del otro.

Así pues, del mismo modo que opera el efecto de sentido en el ámbito lingüístico, Derrida considera que la jerarquía epistemológica de la mismidad trabaja sobre el mecanismo de la definición excluyente: la mismidad se autoproclama el origen del sentido, obvia o silencia cualquier otro sentido, lo invisibiliza, y naturaliza dicha jerarquía. Por tanto, la propuesta epistemológica para atender a la alteridad consiste en problematizar, desnaturalizar y diseminar tales definiciones siguiendo su genealogía a fin de desvelar sus inconsistencias e intereses ocultos en favor de la alteridad excluida.

18 P. Vidarte, "Filosofías de la diferencia", en Filosofías del siglo XX, Madrid, Síntesis, 2005, pp. 258-266. En Derrida en castellano: <https://redaprenderycambiar.com.ar/derrida/comentarios/ derrida_paco-vidarte.htm>.

19 M. Foucault, El pensamiento del afuera, trad. de M. Arranz Lázaro, Valencia, Pretextos, 2008.

20 E. Lévinas, Totalidad e infinito. Ensayo sobre la exterioridad, trad. de M. García Baró, Salamanca, Sígueme, 2002. 
Pensar la genealogía estructurada de sus conceptos de la manera más fiel, más interior, pero al mismo tiempo, desde cierto afuera por ella incalificable, innombrable, determinar lo que esta historia ha podido disimular o prohibir, convirtiéndose en historia por medio de esta represión que de alguna manera es interesada ${ }^{21}$.

Consecuentemente, pasando ahora desde la perspectiva epistemológica a la ontológica, el funcionamiento categorial de la Metafísica de la presencia se puede resumir, a juicio de Derrida, en los siguientes pasos. Ante un acontecimiento de diferición indivisible, como podría ser una realidad cambiante en su devenir, lo polariza, y simultáneamente jerarquiza la oposición. Derrida lo ejemplifica de forma muy clara con el caso de lo que podríamos calificar como el acontecimiento de la existencia en su devenir.

Visto de forma holística, el devenir de la existencia es una realidad en la cual no se puede distinguir de forma polarizada qué es la vida y qué es la muerte, y en el que sin embargo, sí que categorizamos dos conceptos excluyentes, dos nociones estáticas y enfrentadas, "vida" frente a "muerte", y a la vez jerarquizamos la "vida" sobre la "muerte" sobre la base de la definición exclusiva: "vida" se define como presencia, y todo el campo semántico del sentido, la luz, la conciencia; y en cambio, "muerte" se define como el fin de la vida, el fin del sentido, el fin de la luz, el fin de la conciencia, la ausencia, el sinsentido, la oscuridad, o lo que es lo mismo, "muerte" sólo queda contemplada como lo no-contemplable, sin definición propia, sencillamente es lo excluido de la noción de "vida", exclusión gracias a la cual la noción de "vida" puede funcionar de manera consistente. Pero el acontecimiento es la diferencia: la presencia sólo es ausencia diferida y viceversa.

Con este ejemplo, se comprende fácilmente cómo se edifica una ontología que categoriza el devenir sobre el par conceptual constituido por "presencia” frente a "ausencia”. La "presencia” entendida como sustancia, punto de existencia "aquí y ahora”, asume el rango de origen pleno de sentido tempo-lineal; quedando "ausencia" definida como la no-sustancia, no-existencia. Ubicar en el lado positivo al colonizador; y en el lado

21 J. Derrida, Posiciones, ob, cit., entrevista con H. Ronse, p. 12. En Derrida en castellano: <https:// redaprenderycambiar.com.ar/derrida/textos/implicaciones.htm>, [consulta: 30/04/2020]. 
negativo al colonizado es una de las tantas consecuencias visibles de un sistema onto-logo-fonocéntrico que se retroalimenta negando la existencia o la presencia a su excluido.

Ahora se comprende de forma clara la crítica derridiana a la tradición en todas sus facetas. Mientras que en la dimensión epistemológica tenemos la crítica al logo-fonocentrismo y el cuestionamiento del par "sentido dominante"/ "sinsentido invisibilizado", en la dimensión ontológica se cuestiona el par "presencia"/ "ausencia”, y en conjunto se pone en tela de juicio la jerarquización de la "mismidad" frente a "alteridad radical"; lo contemplable frente a lo incontemplable.

Se hace evidente que de estos principios solo puede deducirse una ética que relacione identidades excluyentes económico-restitutivamente; y una política con una democracia de la hospitalidad condicional y economía restitutiva. O lo que es lo mismo, una justicia que solo toma en consideración a los que fueron definidos como presencia y que deja en el silencio a todo lo demás. Deconstruir tal sistema adquiere un propósito profundamente ético ya que al excluir al otro de la comunidad lingüística y negarle la capacidad de respuesta se lo excluye de toda posibilidad de relación.

Con este propósito, Derrida asume una metafísica de la diferencia, acepta la impureza tanto en unos como en otros, o lo que es lo mismo, el fin del dominio natural del que se define puro, y va más allá de la relación económica y de la hospitalidad. El argumento derridiano expone que si entendemos la relación con la alteridad bajo los parámetros de anfitrión y huésped, no se abre espacio real, pues el anfitrión acepta sólo al huésped que es asimilable, es decir, al que cumple sus categorías. En cambio, si superamos sus límites hacia la hostipitalidad, y transgredimos las posiciones de dominante y dominado en favor de una idea de acogimiento que supere la capacidad del anfitrión, sí que abrimos espacio, no solo a lo asimilable para acoger una mismidad, sino al acontecimiento de lo inesperado que cambiará la definición del mismo, pues realmente es la experiencia de un acontecimiento que alterará las definiciones previas de mismo y de otro.

La incondicionalidad de la hospitalidad debe ser infinita y, por consiguiente, heterogénea a las condiciones legislativas, políticas, etc. dicha 
heterogeneidad no significa oposición. Para que esa hospitalidad incondicional se encarne, para que se torne efectiva, es preciso que se determine y que, por consiguiente, dé lugar a unas medidas prácticas, a una serie de condiciones y de leyes, y que la legislación condicional no olvide el imperativo de la hospitalidad al que se refiere ${ }^{22}$.

No es extraño que la estrategia deconstructiva haya sido desarrollada por los estudios postcoloniales, movimientos feministas, LGTBQ, antiespecistas, de ecocrítica, entre otros, pues ofrece el aparato crítico para atender al problema de la definición y desvelar el mecanismo de poder subyacente.

En este caso concreto, y brevemente, la deconstrucción permite articular la crítica al androcentrismo demostrando que su hegemonía se erige sobre la exclusión de, entre otros muchos, "el esclavo", "el colono", "el extranjero", "la mujer", "el homosexual", "el animal"23, etc. Se comprueba a simple vista que el mecanismo de definición de cada uno de estos "otros" se basó en la negación arbitraria de las características que se le atribuían al dominante y la posterior abstracción en singular que neutraliza la concreción indispensable para el trato ético: una vez cosificado por definición queda justificada su explotación.

El esclavo es aquél que "no es amo", el colono es el que "no es colonizador", el extranjero es el que "no es de aquí", la mujer es todo lo contrario al hombre, en valores y facultades; el homosexual también; el animal es un ser no racional, sin capacidad de respuesta, sin capacidad de sufrimiento incluso. Al definirlos por negación, por silenciamiento, se les excluye de la comunidad ética-dialógica, ya que no pueden expresarse en el sistema, lo que conduce a pensar como natural, normal e incluso necesaria su invisibilidad. Sin embargo, solo siguiendo la genealogía de su conceptualización se vislumbran los intereses que apuntalan los sentidos vigentes, y tales grietas, el rastro de lo excluido en forma de silencio.

22 J. Derrida, “Sobre la hospitalidad”, en ;Palabra!, Madrid, Trotta, 2001, p. 53.

23 Véase por ejemplo J. Derrida, El animal que luego estoy si(gui)endo, trad. de C. de Peretti y C. Rodríguez Marcial, Madrid, Trotta, 2008. Derrida, J. y Roudinesco, É., "Violencia contra los animales”, en Y mañana qué, trad. de V. Goldstein, Buenos Aires, F.C.E., 2009, pp. 9-28. Así como E. Zarzo, "Différance Animal/ Humano: Deconstrucción epistemológica”, en Pangeas. Revista Interdisciplinar de Ecocrítica, Asociación Interdisciplinar Iberoamericana de Literatura y Ecocrítica, 2019, vol. 1., núm 1, pp. 20-27. 
Ninguna justicia parece posible o pensable sin un principio de responsabilidad, más allá de todo presente vivo, en aquello que desquicia el presente vivo, ante los fantasmas de los que aún hoy no han nacido o de los que han muerto ya, víctimas o no de guerras, de violencias políticas o de otras violencias, de exterminaciones nacionalistas, racistas, colonialistas, sexistas o de otro tipo; de las opresiones del imperio capitalista o de cualquier forma de totalitarismo ${ }^{24}$.

\section{Crítica Deconstructiva y Lo Otro POR-VENIR}

Sin duda, la estrategia derridiana permite cuestionar toda hegemonía ontológico-epistemológica basada en la categoría de sujeto excluyente, dedicada a la repetición y despliegue de sí misma. Derrida acepta que la Mitología Blanca sigue funcionando con su mecanismo de la identidad excluyente; pero también que la deconstrucción, si es alguna cosa, es una actitud ética irrenunciable, y por tanto continúa con la misma insistencia que dicha Mitología. Precisamente éste es el principio derridiano, mantener la actitud ética, pues mientras haya sentido excluyente, habrá un excluido.

Más vale la apertura del porvenir: éste es el axioma de la deconstrucción, aquello a partir de lo cual siempre se ha puesto en movimiento, y lo que la liga, como el porvenir mismo, con la alteridad, con la dignidad sin precio de la alteridad, es decir, con la justicia. (...) Lo indeconstructible, si lo hay, sería la justicia. ${ }^{25}$

Es fácil comprobar a diario cómo se intenta desactivar la actitud ética. Ante cualquier problemática se opera la escisión entre "los unos" y "los otros" en ambos lados. Por una parte, se nos ubica falsamente en el lado positivo de la identidad excluyente, silenciando todo lo que definimos como distinto, y relegándolo a un espacio abstracto donde no hace falta establecer relación ética; y por otra parte, se divide a los excluidos por el sistema, como si fueran luchas identitarias distintas, siendo que la identidad dominante que las silencia es la misma. Se genera así una falsa autocomplacencia en el mismo ante la exclusión del otro, olvidando que en cualquier momento puede ser ese otro; y los excluidos están divididos.

24 J. Derrida, Espectros de Marx. El estado de la deuda, el trabajo del duelo y la nueva internacional, trad. de J. M. Alarcón y C. de Peretti, Valladolid, 1998, p. 13.

25 J. Derrida, La deconstrucción de la Actualidad, ob. cit., Pg. 70. 
Pero aquí de nuevo Derrida despliega las dos caras del efecto de sentido. Bajo su criterio, de un lado, la Metafísica de la presencia, por su propio funcionamiento conduce al colapso, ya que al operar por exclusión y silenciamiento de lo otro, en realidad genera una especie de autoinmunidad que va en detrimento de su capacidad de adaptación a los acontecimientos ${ }^{26}$. En su afán de mantenerse en el efecto de sentido puro, anula todo trato con lo que considera lo otro, y entonces el sistema de la presencia se torna inútil para tratar con aquellos que funcionan de forma invisible, en las ranuras del sistema, pues, de hecho, se le da impunidad en la práctica por haberlo calificado como lo impensable. Con una lógica contaminada, en cambio, se podría atender a lo que habita el sistema, y tratar con su cotidiano asedio desde dentro, reconociéndolo.

De otra parte, abrir espacio a la alteridad equivale a dislocar la falaz fundamentación por petición de principio del sujeto exclusivo, y su supuesta lógica económica, en favor del reconocimiento de todos los excluidos. La crítica en aras del irreductible a tales categorías desvela las fisuras de un sistema que segrega, desecha, expulsa, anula y marginaliza. La estrategia ético-política que subyace a la deconstrucción es un contrapoder, que no es nada minoritario, y es perfectamente capaz de afrentar la ética dominante que la anula, desedimentando sus sentidos.

En conclusión, mantener un concepto de sujeto onto-logo-fonocéntrico como núcleo interpretativo de una ontología jerarquizadora, epistemológicamente ciego a la alteridad y éticamente depredador, en una sociedad como la actual es anclarse en una cosmovisión excluyente y fagocitadora, que, de hecho, niega sus fallos estructurales y por tanto impide las nuevas soluciones. En cambio, plantear un sujeto híbrido, con una conciencia diferencial, sin complacencia intelectual, dedicado a desnaturalizar los intentos de purificación, y con ello permitir la apertura constante a la in-venida de lo otro, en una apertura ética a lo por-venir es el legado derridiano que siempre está por heredar.

26 J. Derrida, Autoinmunidad: Suicidios simbólicos y reales (entrevista de Giovanna Borradori con Jacques Derrida el 22 de octubre de 2001 en Nueva York. Traducido del francés por J. Botero), en La filosofía en una época de terror. Diálogos con Jürgen Habermas y Jacques Derrida, Buenos Aires, Taurus, 2004. Disponible en línea: <http://www.jacquesderrida.com.ar/textos/septiembre.htm>, [consulta: 30/04/2020]. 
La democracia sigue estando por venir, esa es su esencia en cuanto sigue estando: no sólo seguirá siendo indefinidamente perfectible, y en consecuencia siempre insuficiente y futura, sino que, al pertenecer al tiempo de la promesa, seguirá estando siempre, en cada uno de sus tiempos futuros, por venir: incluso cuando hay la democracia, ésta no existe, no está jamás presente, sigue siendo el tema de un concepto no presentable ${ }^{27}$. 